\title{
Comparisons of electron acceleration efficiency among different structures during magnetic reconnection: a Cluster multicase study
}

\author{
M. Zhou ${ }^{1,2}$, T. Li ${ }^{1,3}$, X. Deng ${ }^{1}$, S. Huang ${ }^{4}$, and H. $\mathbf{L i}^{5}$ \\ ${ }^{1}$ Institute of Space Science and Technology, Nanchang University, Nanchang 330031, China \\ ${ }^{2}$ State Key Laboratory of Space Weather, Chinese Academy of Sciences, Beijing 100190, China \\ ${ }^{3}$ School of Sciences, Nanchang University, Nanchang 330031, China \\ ${ }^{4}$ School of Electronic and Information, Wuhan University, Wuhan 430072, China \\ ${ }^{5}$ School of Physics and Optoelectronic Engineering, Xidian University, Xi' an 710071, China
}

Correspondence to: M. Zhou (mengzhou@ncu.edu.cn)

Received: 10 March 2015 - Revised: 29 September 2015 - Accepted: 17 November - Published: 1 December 2015

\begin{abstract}
Magnetic reconnection has long been believed to be an efficient engine for energetic electrons production. Four different structures have been proposed for electrons being energized: flux pileup region, density cavity located around the separatrix, magnetic island and thin current sheet. In this paper, we compare the electron acceleration efficiency among these structures based on 12 magnetotail reconnection events observed by the Cluster spacecraft in 2001-2006. We used the flux ratio between the energetic electrons $(>50 \mathrm{keV})$ and lower energy electrons $(<26 \mathrm{keV})$ to quantify the electron acceleration efficiency. We do not find any specific sequence in which electrons are accelerated within these structures, though the flux pileup region, magnetic island and thin current sheet have higher probabilities to reach the maximum efficiency among the four structures than the density cavity. However, the most efficient electron energization usually occurs outside these structures. We suggest that other structures may also play important roles in energizing electrons. Our results could provide important constraints for the further modeling of electron acceleration during magnetic reconnection.
\end{abstract}

Keywords. Space plasma physics (magnetic reconnection)

\section{Introduction}

Electron energization is an outstanding issue in plasma physics and astrophysics. Magnetic reconnection is able to produce a large number of energetic electrons (Sonnerup, 1979). In the terrestrial magnetosphere, hundreds of $\mathrm{keV}$ electrons were detected in the reconnection region (e.g.
Øieroset et al., 2002). In the past decade, there have been many theoretical models and observations about electron acceleration during magnetic reconnection.

Electrons can be accelerated within thin current sheet in the vicinity of X-line (Pritchett, 2006; Retino et al., 2008). They are accelerated by the reconnection electric field either adiabatically (with guide field) or non-adiabatically (without guide field) within the thin current sheet, where they drift against the out-of-plane reconnection electric field. Significant energetic electron fluxes increase has been observed in the magnetic islands and/or flux ropes associated with reconnection (Chen et al., 2008; Huang et al., 2012a). Drake et al. (2006) proposed a Fermi-type acceleration mechanism in multiple X-lines reconnection. Electrons gain energy as the island is contracting. Magnetic separatrix has also received huge attention on electron acceleration. It was shown that parallel electric field exists inside the density cavity around the separatrix. Electrons streaming along the separatrix can be accelerated by this parallel electric field (Drake et al., 2005; Pritchett, 2006). Wang et al. (2013) reported the co-existence of $\sim 100 \mathrm{keV}$ electrons and patchy parallel electric field inside a density cavity at the separatrix region. However, there is negative result that energetic electron fluxes decreased inside a density cavity (Zhou et al., 2011). A secondary acceleration at the magnetic flux pileup region downstream of X-line was proposed by Hoshino et al. (2001). They suggested that electrons can be energized by inductive electric field at the flux pileup region due to their gradient-B or curvature-B drift against the electric field. This scenario was confirmed by the follow-up satellite ob- 
servation (Imada et al., 2007). In addition, recent observations found that the flux pileup region can propagate far away from X-line in the magnetotail. The flux pileup region usually has a sharp leading boundary, which is called dipolarization front (e.g. Zhou et al., 2009). Electrons can be accelerated around the front by adiabatic betatron and Fermi acceleration, or non-adiabatic acceleration through wave-particle interactions (Ashour-Abdalla et al., 2011; Deng et al., 2010; Fu et al., 2013; Huang et al., 2012b). In summary, thin current sheet, magnetic island, density cavity around the separatrix and flux pileup region are four different structures which are frequently involved in electron energization during reconnection. The locations of these structures in the context of 2-D reconnection geometry are depicted in Fig. 1.

Huang et al. (2012a) experimentally compared the energetic electron fluxes within a thin current sheet and a magnetic island in a diffusion region. They found that flux within the island was larger than that within the thin current sheet. Based on this they suggested that electrons were first accelerated in the current sheet and further energized inside the island. Their study raises some interesting questions: does any specific sequence exist in which electrons are accelerated through these structures (Hoshino et al., 2001; Huang et al., 2012a; Imada et al., 2007)? At which structure is the electron acceleration the most efficient? In this paper we extend their study by comparing the energetic electron acceleration efficiency among these different structures during multiple reconnection events in the Earth's magnetotail.

\section{Observation}

Multiple instruments of Cluster spacecraft were used in this study, including the fluxgate magnetometer (FGM) (Balogh et al., 2001), the electric fields and waves (EFW) (Gustafsson et al., 2001), the Cluster ion spectrometry (CIS) (Rème et al., 2001), the plasma electron and current experiment (PEACE) (Johnstone et al., 1997), and the research with adaptive particle imaging detectors (RAPID) (Wilken et al., 2001). Only the data points with values above the background noise and that were also flagged with quality number 3 or 4 (good for publication) were used from PEACE. Magnetic field and plasma flow are presented in the geocentric solar magnetospheric (GSM) coordinate, while the electric field is shown in the ISR2 (inverted spacecraft reference) coordinate. Temporal resolutions for magnetic and electric fields are $22.3 \mathrm{~Hz}$ and $25 \mathrm{~Hz}$ respectively. Electron density with resolution of $0.2 \mathrm{~s}$ was inferred from the spacecraft potential (Pedersen et al., 2008).

Our database consists of reconnection events in the Earth's magnetotail during the years 2001-2006 (Zhou et al., 2014). We chose the events in which correlated flow $V_{x}$ and magnetic field $B_{z}$ reversal were detected. In addition, the polarizations of out-of-plane magnetic fields $B_{y}$ and normal electric fields $E_{z}$ that consistent with the conventional Hall fields

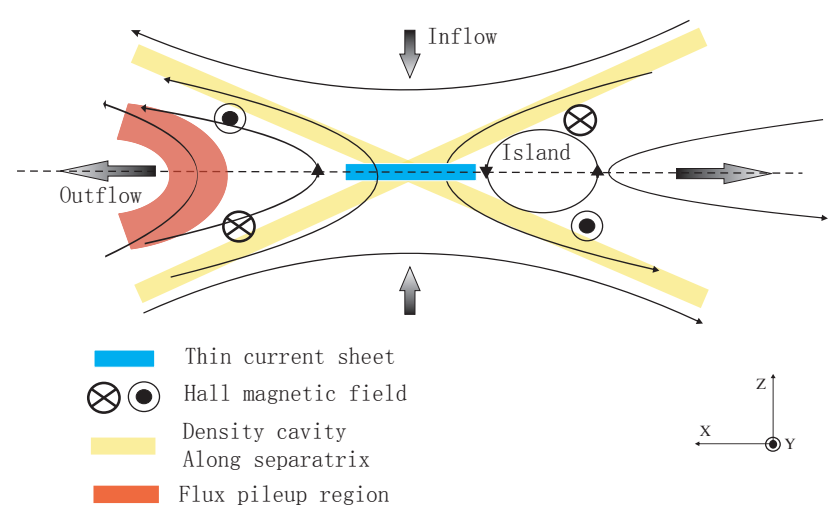

Figure 1. Schematic view of the 2-D reconnection geometry and the proposed structures for electron acceleration.

were also detected during the flow reversal, which confirms that the spacecraft were very close to $\mathrm{X}$-line.

The accuracy of identifying the aforementioned four structures is crucial for this study. Below we discuss and list our criteria.

\section{Thin current sheet}

We define the thin current sheet as ion-scale current sheet, the thickness of which is around the local proton inertial length $d_{i}$. Here $d_{i}=c / \omega_{\text {pi }}$ is based on the proton density in the current sheet measured by CIS. If four spacecraft have all crossed the sheet, then we employed the well-known timing method to estimate the sheet thickness. This method is available when the spacecraft inter-distance is much smaller than the current sheet width. If less than four spacecraft have crossed the sheet, we resort to a less accurate and less straightforward method. This method requires two spacecraft being located on the opposite side of current sheet, i.e. one in the Northern Hemisphere while the other in the Southern Hemisphere. In this situation the current sheet thickness should be close or less than the distance between the two spacecraft along the $Z$ direction.

2. Flux pileup region

a. $\left|B_{z}\right|$ increases more than $5 \mathrm{nT}$ in $20 \mathrm{~s} . B_{z}$ can be either positive or negative. When $B_{z}$ is positive (negative) the corresponding plasma flow should be earthward (tailward).

b. The associated maximum equatorial plasma flow speed should be greater than $150 \mathrm{~km} \mathrm{~s}^{-1}$, i.e., $\sqrt{v x^{2}+v y^{2}}>$ 150 .

\section{Magnetic island}

a. $B_{z}$ exhibits a nearly symmetric bipolar change, and $B_{y}$ has an enhancement or dip at the center (i.e., double peak structure) (Borg et al., 2012; Chen et al., 2008). 
Highly asymmetric bipolar $B_{z}$ structure is probably the dipolarization front.

4. Density cavity around the separatrix

a. The spacecraft should be away from current sheet, which means that $\left|B_{x}\right|$ is not very small. Here we require that $\left|B_{x}\right|>5 \mathrm{nT}$.

b. It corresponds to large density variations (density should decrease at least fivefold) and electric field fluctuations $\left(|\delta E|>10 \mathrm{mV} \mathrm{m}^{-1}\right.$ ) (Cattell et al., 2005; Zhou et al., 2011).

It should be noted that structures located on the high latitude and tailward of X-line may contain electrons from the distant reconnection site, so these structures are eliminated from our database.

In this paper, acceleration efficiency is defined as the proportion of energetic electrons in the whole energy distribution. We used the flux ratio of energetic electrons to lower energy electrons to quantify the efficiency. Here we used electrons measured by RAPID $(50.5-244.1 \mathrm{keV})$ to represent energetic electrons, which is in accord with many previous studies (e.g. Chen et al., 2008). Fluxes of the first energy channel of RAPID occasionally have abnormal fluctuations and/or spikes (not shown), so we did not use it. PEACE measures electrons in the range of approximately $5 \mathrm{eV}-26 \mathrm{keV}$. Electrons with energy less than $70 \mathrm{eV}$ may be contaminated by photoelectrons, so we set the lower energy boundary for thermal electrons as $100 \mathrm{eV}$. Hence we used electrons from $100 \mathrm{eV}$ to $26 \mathrm{keV}$ measured by PEACE to represent lower energy electrons. Figure 2 presents an energy distribution to show the energy ranges for energetic and lower energy electrons. This ratio has been employed by Imada et al. (2011) to compare the electron acceleration efficiency among different reconnection events. It is a more reliable parameter than the flux magnitude to indicate the electron acceleration efficiency. Relying on flux magnitude may misinterpret some pseudo acceleration event. For instance, the density variation can lead to flux variation even if the energy distribution does not change. If a spacecraft moves from lower density plasma to higher density plasma with density increases by a factor of two, it will measure a two times increase of energetic particle flux even if the energy distributions are the same in these two plasmas. However, this flux increase is not due to acceleration but merely a plasma compression.

Small-scale or transient structures, the duration of which is less than the spin period $4 \mathrm{~s}$, are not included in this study because the cadence of electron flux data is $4 \mathrm{~s}$. To compare the electron acceleration efficiency among different structures, we chose the events in which at least two different structures were encountered. If one type of structure was detected more than once in one event, or one structure was detected by more than one spacecraft, we chose the one that has the highest flux ratio. Following this we present two events in which all four types of structures were detected by Cluster.

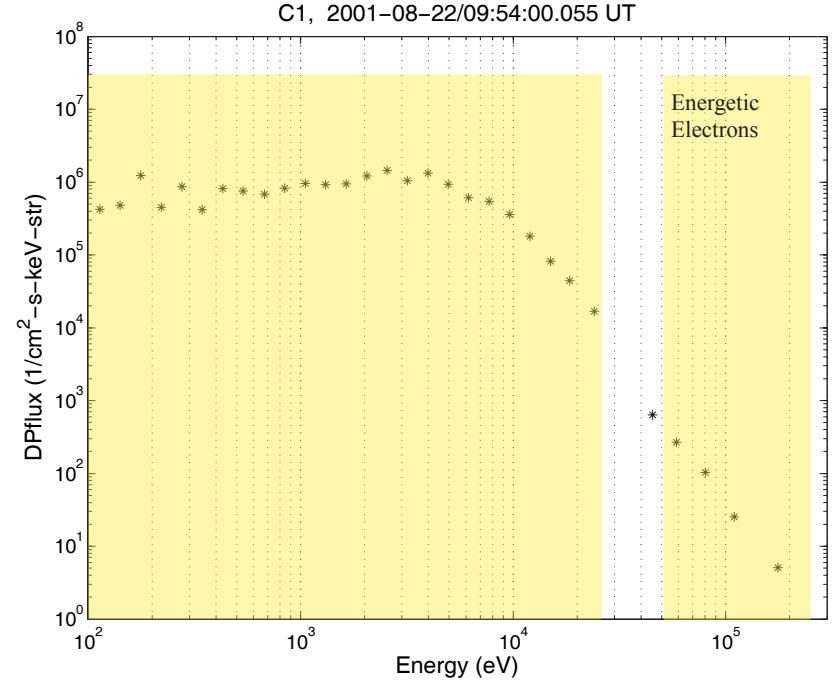

Figure 2. Differential particle flux as a function of energy for $\mathrm{C} 1$ on 22 August 2001 event at around 09:54:00 UT. Yellow shaded regions mark the energy ranges for the energetic and lower energy electrons used to calculate the efficiency.

The first event is between 09:38 and 09:51 UT on 1 October 2001. This event has been extensively studied in many different aspects, such as diffusion region structure and electron energization (e.g. Runov et al., 2003; Cattell et al., 2005; Chen et al., 2008). Figure 3 presents the four structures observed by Cluster. The upper left plot (Fig. 3a) shows the $\mathrm{C} 1$ observation of a density cavity around 09:50:10-09:50:20 UT. The density cavity is manifested as a sharp density drop (from 0.3 to $0.03 \mathrm{~cm}^{-3}$ ). It corresponds to a large $B_{x}(\sim 20 \mathrm{nT})$ and intense electric field fluctuations $\left(>100 \mathrm{mV} \mathrm{m}^{-1}\right)$. The upper right plot (Fig. 3b) shows the $\mathrm{C} 3$ observation of a magnetic island around 09:47:10-09:47:20 UT. This island is manifested as bipolar $B_{z}$ and evident enhancement of core field $\left|B_{y}\right|$. The two sides of island moved in opposite direction as there was a flow reversal inside the island. The convergent flow inside the island was originated from the two active X-lines binding the island (Deng et al., 2004; Zhou et al., 2012). The lower left plot (Fig. 3c) shows the C3 observation of a flux pileup region around 09:48:46-09:48:52 UT. We see a rapid $B_{z}$ increase ( $>15 \mathrm{nT}$ in less than $10 \mathrm{~s}$ ) at the leading edge of a fast earthward flow. The lower right plot (Fig. 3d) shows the $\mathrm{C} 2$ observation of a thin current sheet around 09:46:33-09:46:40 UT. The thickness of the current sheet is about $700 \mathrm{~km} \sim 1.4 c / \omega_{\text {pi }}$ (based on the local plasma density $0.2 \mathrm{~cm}^{-3}$ ). We note that all the above-identified structures are consistent with our criteria. The maximum flux ratios within the density cavity, magnetic island, flux pileup region and thin current sheet are $(1.8 \pm 0.3) \times 10^{-4},(9.4 \pm 0.3) \times 10^{-4}$, $(11.6 \pm 0.4) \times 10^{-4}$ and $(3.5 \pm 0.6) \times 10^{-4}$ respectively. The error bar indicates the standard deviation of flux measure- 
(a) $\mathrm{C} 1$

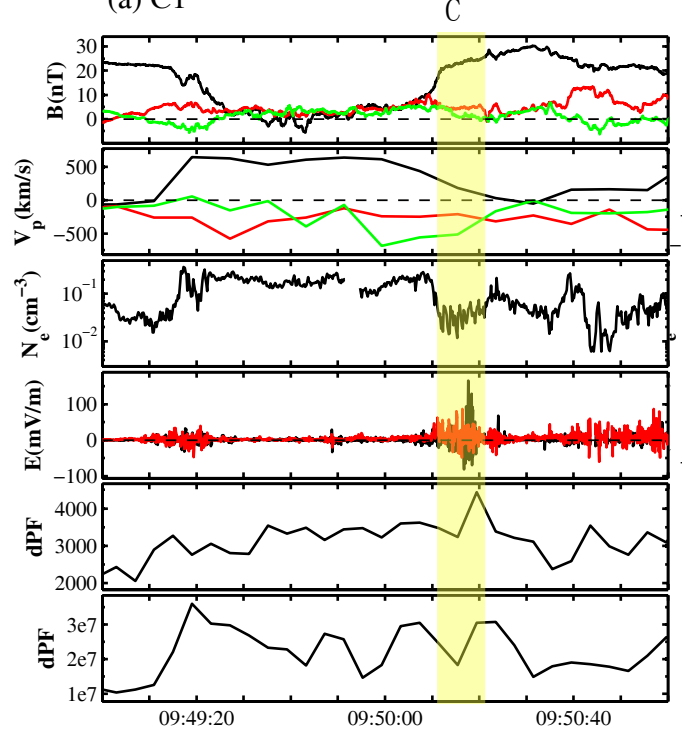

(c) $\mathrm{C} 3$

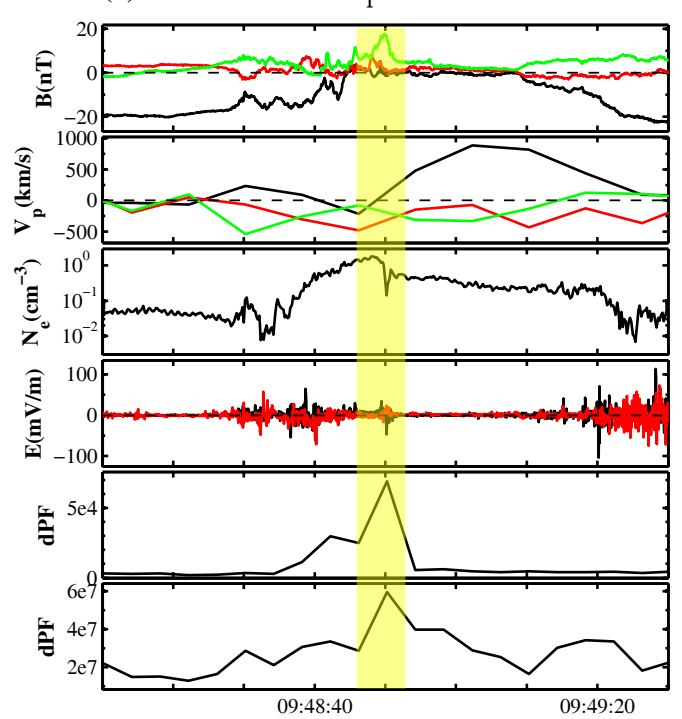

(b) $\mathrm{C} 3$

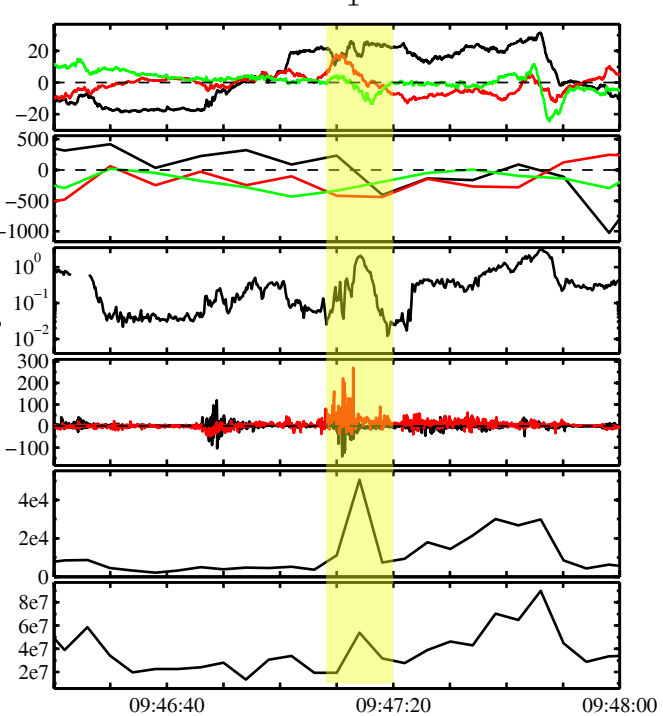

(d) $\mathrm{C} 2$ S

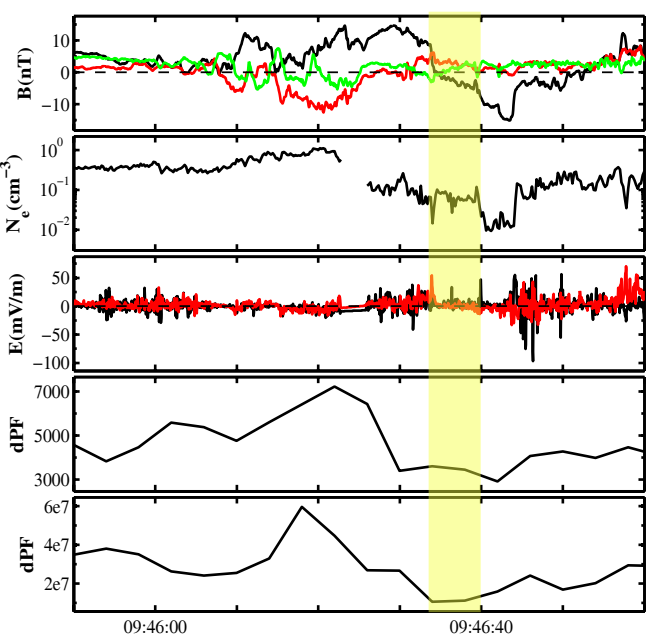

Figure 3. Observations of four structures on 1 October 2001 event: (a) density cavity by C1, (b) magnetic island by C3, (c) flux pileup region by $\mathrm{C} 3$ and (d) thin current sheet by $\mathrm{C} 2$. Each plot in Fig. 3a-d shows (From the top to bottom) three components of magnetic fields (black: $B_{x}$, red: $B_{y}$, green: $B_{z}$ ), three components of plasma bulk velocity (black: $V_{x}$, red: $V_{y}$, green: $V_{z}$ ), two components of electric fields, electron density, energetic electron differential particle flux (integrated in the range of 50.5-244.1 keV), and lower energy electron differential particle flux (integrated in the range of $0.1-26 \mathrm{keV}$ ). The shaded areas mark the identified structures. Because the CIS instrument of C2 is out of order, panel (d) does not show the plasma bulk velocity.

ments by RAPID. We see that the ratios in the flux pileup region and magnetic island are higher than those inside the other two structures. The maximum flux ratio recorded in this event is $(11.6 \pm 0.4) \times 10^{-4}$, which is the same as the flux ratio inside the flux pileup region.

Another event is between 09:41 and 09:57 UT on $22 \mathrm{Au}-$ gust 2001. This event has been studied by Eastwood et al. (2007). They reported the Hall magnetic and electric fields in the ion diffusion region from both hemispheres. Figure 4 presents the four structures observed by different space- craft. The upper left plot (Fig. 4a) shows the C1 observation of a flux pileup region around 09:42:51-09:42:58 UT. The upper right plot (Fig. 4b) shows the $\mathrm{C} 1$ observation of a thin current sheet around 09:53:54-09:54:02 UT. The current sheet thickness is about $450 \mathrm{~km} \sim 1.1 \mathrm{c} / \omega_{\mathrm{pi}}$ (based on the local plasma density $0.3 \mathrm{~cm}^{-3}$ ). The lower left plot (Fig. 4c) shows the $\mathrm{C} 2$ observation of a density cavity around 09:42:37-09:42:44 UT. The cavity was located around a separatrix, which corresponds to a large $B_{x}$ and intense electric field fluctuations. The lower right plot (Fig. 4d) 
(a) $\mathrm{C} 1$

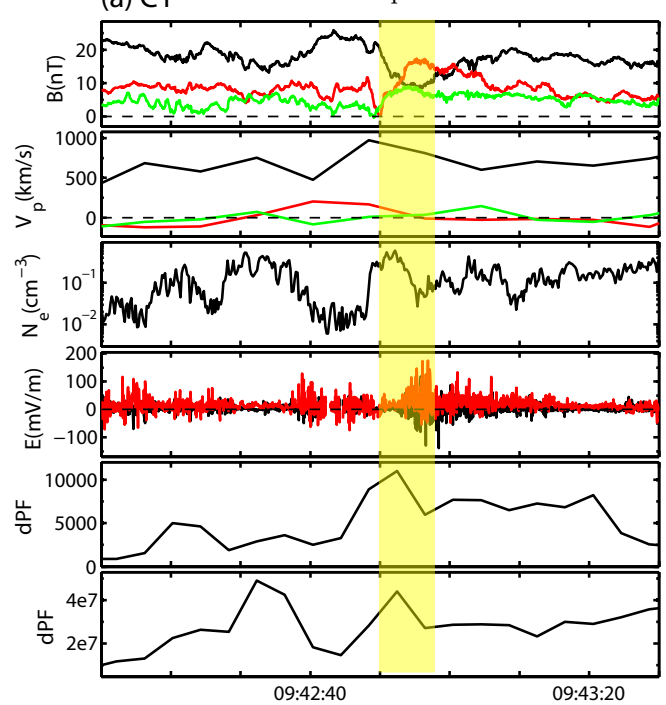

(c) $\mathrm{C2}$

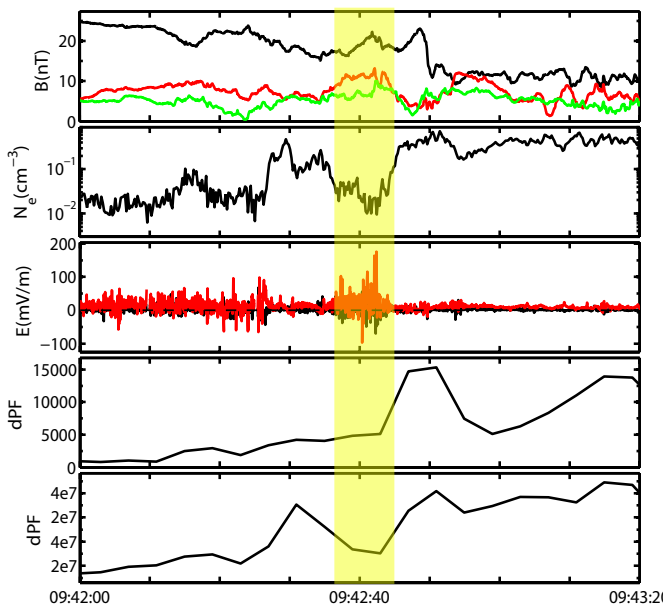

(e) $\mathrm{C} 1$

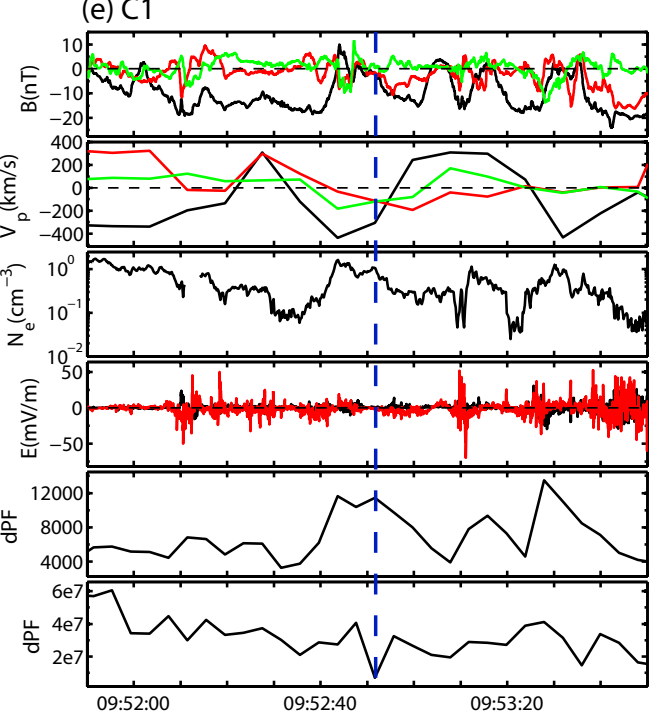

(b) $\mathrm{C} 1$

S

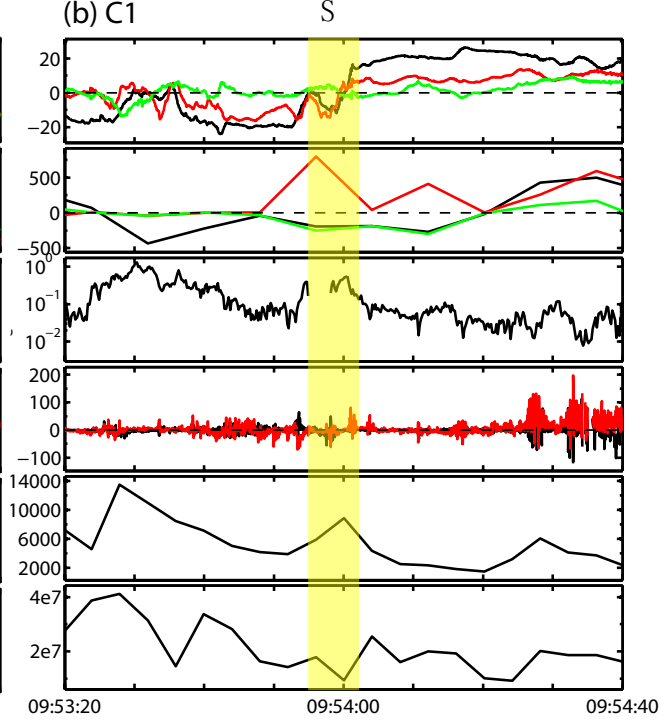

(d) $\mathrm{C2}$

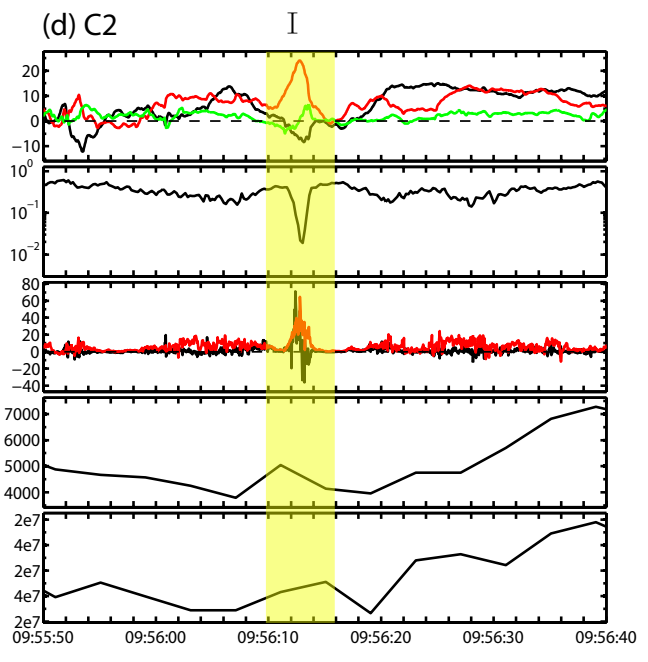

09.55 .50
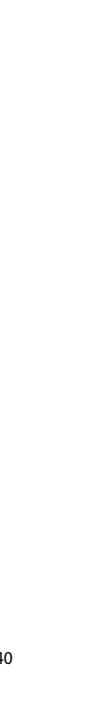

.

$$
\text { 我 }
$$


shows the $\mathrm{C} 2$ observation of a magnetic island around 09:56:10-09:56:16 UT. All the above structures are consistent with our criteria. The maximum flux ratios within the flux pileup region, density cavity, thin current sheet and magnetic island are $(2.5 \pm 0.2) \times 10^{-4},(3.4 \pm 0.5) \times 10^{-4}$, $(9.5 \pm 1.0) \times 10^{-4}$ and $(2.3 \pm 0.3) \times 10^{-4}$ respectively. The ratio in the thin current sheet is higher than those in the other structures. This is different from the October 01, 2001 event in which the flux pileup region has a higher ratio than the other three structures. The maximum flux ratio in this event is $(16.4 \pm 1.5) \times 10^{-4}$. This value is larger than those measured in the four structures. Panel e shows that it occurred inside the current sheet and tailward flow. It corresponds to the increase of high energy electron flux and decrease of lower energy electron flux, and relatively low electric field fluctuations.

Overall, there are 12 events that have more than one structures detected by Cluster. Detailed parameters of these structures are listed in Table 1. Symbol "P" denotes flux pileup region, "C" denotes density cavity, " $\mathrm{S}$ " denotes thin current sheet and "I" denotes magnetic island. The power law indices of energetic electrons (by using four energy channels from 50.5 to $244.1 \mathrm{keV}$ ) are also calculated for reference. In order to reduce the statistical uncertainties, the power law index was calculated only if the integrated energetic electron flux was greater than $1000 /\left(\mathrm{s} \mathrm{sr} \mathrm{cm}^{2}\right)$. For each event we sort the structures in order of the flux ratio from high to low. Two values are indistinguishable if the error bars are overlapped with each other.

From Table 1 we see that the order of electron acceleration efficiency is different in different events. For instance, the sequence is S-C-P-I in the 22 August 2001 event according to the efficiency from high to low, while the sequence is I-PC-S in the 19 September 2003 event. The number of events that flux pileup region has the highest efficiency among these structures is 5, while the number of events that flux pileup region was detected is 11 . Hence the occurrence rate that flux pileup region has the highest efficiency is $5 / 11$. The two numbers for density cavity are 1 and 9 , for magnetic island are 2 and 8, and for thin current sheet are 3 and 9. For simplicity, we call the evens that flux pileup region has the highest efficiency among the four as P-type events. Similarly we define other three types of events: C-type, S-type and I-type events. We see that all four type events exist in the 12 reconnection events. And the occurrence rates of P-type, I-type and S-type event are similar, while they are greater than the occurrence rate of C-type event. Furthermore, we calculated the maximum flux ratio ever measured for each event (rightmost column of Table 1). It is shown that, only in four events (12 September 2001, 1 October 2001, 14 September 2004 and 28 August 2005), the maximum ratio occurs inside these four structures. The maximum efficiency occurs outside the four structures for the majority of events.

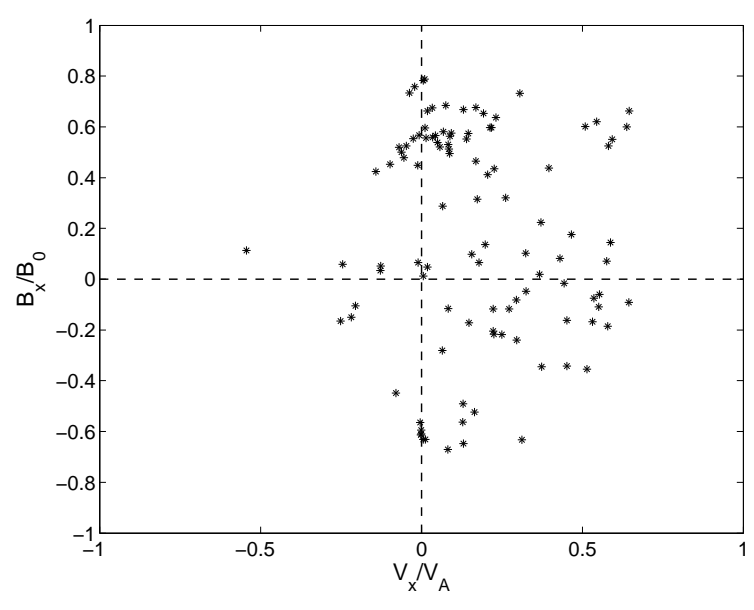

Figure 5. A scatterplot of locations of the most efficient energizations as a function of $B_{x}$ and $V_{x} . B_{x}$ and $V_{x}$ have been normalized by the asymptotic magnetic field $B_{0}$ and Alfven speed based on $B_{0}$ and $n_{0}$; here $n_{0}$ is the plasma density in the central current sheet. Data points with top $3 \%$ electron acceleration efficiency for each event are plotted.

\section{Discussion and summary}

In this paper, we study the electron acceleration efficiency in reconnection region by examining 12 reconnection events in the magnetotail observed by Cluster spacecraft. The flux ratio of (50.5-244.1) to (0.1-26) keV electrons is employed to quantify the electron acceleration efficiency. We compared the electron acceleration efficiency within the following four structures: thin current sheet, density cavity around the separatrix, magnetic island and flux pileup region. We find that the occurrence rates of P-type, I-type and S-type events are higher than the occurrence rate of C-type event. However, we do not find consistent order of efficiency among these four structures through the analysis of the 12 events, which implies that there is no specific sequence in which electrons are energized through these structures. Through a statistical study of energetic electrons in the magnetotail reconnection region, Zhou et al. (2015) found that the electron acceleration efficiency is positively correlated to the plasma outflow speed $V_{x}$. Because there is no specific order of outflow speed associated with the four structures, it is understandable that there is no specific sequence of electron acceleration through the four structures. Another possible reason is probably the electron acceleration is not confined in the four structures but occurs in a wider region. Using large-scale PIC simulations, Egedal et al. (2012) showed that electron acceleration occurs within a large fraction of reconnection exhaust, including the density cavity along the separatrix and magnetic island etc. Furthermore, Dahlin et al. (2015) found that in a 3-D system electrons are not confined in a single structure but instead move throughout the reconnection domain due to the stochastic magnetic fields caused by filamentation of 
Table 1. A summary of flux ratio and power law indices within the different structures for all the selected reconnection events. “-” in the

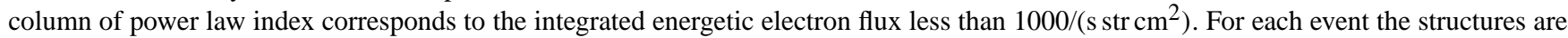
sorted in order of flux ratio from high to low.

\begin{tabular}{|c|c|c|c|c|c|c|c|}
\hline Date & Structure & $\mathrm{SC}$ & Start time & End time & Flux ratio $\left(10^{-4}\right)$ & Power law index & $\begin{array}{l}\text { Max ratio of } \\
\text { the event }\left(10^{-4}\right)\end{array}$ \\
\hline \multirow{4}{*}{22 August 2001} & $\mathrm{~S}$ & $\mathrm{C} 1$ & 09:53:54 & 09:54:02 & $9.5 \pm 1.0$ & -3.7 & $16.4 \pm 1.5$ \\
\hline & $\mathrm{C}$ & $\mathrm{C} 2$ & $09: 42: 37$ & $09: 42: 44$ & $3.4 \pm 0.5$ & -3.3 & \\
\hline & $\mathrm{P}$ & $\mathrm{C} 1$ & $09: 42: 50$ & $09: 42: 58$ & $2.5 \pm 0.2$ & -3.5 & \\
\hline & $\mathrm{I}$ & $\mathrm{C} 2$ & 09:56:10 & $09: 56: 16$ & $2.3 \pm 0.3$ & -3.2 & \\
\hline \multirow[t]{2}{*}{12 September 2001} & $\mathrm{P}$ & $\mathrm{C} 3$ & $13: 15: 18$ & $13: 15: 36$ & $13.6 \pm 1.1$ & -3.2 & $13.6 \pm 1.1$ \\
\hline & I & $\mathrm{C} 2$ & $13: 13: 38$ & $13: 13: 52$ & $3.0 \pm 0.5$ & -2.5 & \\
\hline \multirow[t]{2}{*}{15 September 2001} & $P$ & $\mathrm{C} 1$ & $05: 07: 50$ & 05:08:04 & $2.8 \pm 0.4$ & -4.5 & $4.8 \pm 0.9$ \\
\hline & $\mathrm{S}$ & $\mathrm{C} 3$ & 05:00:54 & 05:01:20 & $1.9 \pm 0.4$ & -3.9 & \\
\hline \multirow[t]{4}{*}{1 October 2001} & I & $\mathrm{C} 3$ & 09:47:08 & $09: 47: 20$ & $9.4 \pm 0.3$ & -4.9 & $11.6 \pm 0.4$ \\
\hline & $\mathrm{P}$ & $\mathrm{C} 3$ & $09: 48: 46$ & $09: 48: 52$ & $11.6 \pm 0.4$ & -4.7 & \\
\hline & $\mathrm{S}$ & $\mathrm{C} 2$ & $09: 46: 33$ & $09: 46: 40$ & $3.5 \pm 0.6$ & -2.1 & \\
\hline & $\mathrm{C}$ & $\mathrm{C} 1$ & 09:50:11 & $09: 50: 21$ & $1.8 \pm 0.3$ & -2.3 & \\
\hline \multirow[t]{2}{*}{8 October 2001} & $\mathrm{~S}$ & $\mathrm{C} 2$ & 13:00:36 & 13:00:56 & $0.7 \pm 0.2$ & - & $2.3 \pm 0.3$ \\
\hline & $\mathrm{P}$ & $\mathrm{C} 3$ & $12: 58: 42$ & $12: 59: 16$ & $0.3 \pm 0.1$ & - & \\
\hline \multirow[t]{3}{*}{21 August 2002} & I & $\mathrm{C} 1$ & 08:10:42 & $08: 11: 12$ & $4.6 \pm 0.6$ & -3.9 & $11.8 \pm 1.3$ \\
\hline & $\mathrm{S}$ & $\mathrm{C} 2$ & 08:08:04 & 08:08:11 & $3.6 \pm 0.6$ & -3.5 & \\
\hline & $\mathrm{P}$ & $\mathrm{C} 4$ & $08: 14: 19$ & $08: 14: 36$ & $3.5 \pm 0.2$ & -5.5 & \\
\hline \multirow[t]{3}{*}{18 September 2002} & I & $\mathrm{C} 4$ & 13:06:31 & 13:07:06 & $2.4 \pm 0.2$ & -2.7 & $3.5 \pm 0.3$ \\
\hline & $\mathrm{P}$ & $\mathrm{C} 3$ & $13: 14: 19$ & $13: 14: 27$ & $1.5 \pm 0.2$ & -2.9 & \\
\hline & $\mathrm{C}$ & $\mathrm{C} 3$ & $13: 13: 21$ & $13: 13: 31$ & $1.2 \pm 0.2$ & -2.8 & \\
\hline \multirow[t]{2}{*}{2 October 2002} & $\mathrm{P}$ & $\mathrm{C} 2$ & $21: 24: 33$ & $21: 24: 41$ & $9.3 \pm 0.8$ & -3.8 & $47.0 \pm 2.3$ \\
\hline & $\mathrm{S}$ & $\mathrm{C} 4$ & $21: 22: 05$ & $21: 22: 18$ & $4.4 \pm 0.7$ & -3.1 & \\
\hline \multirow[t]{4}{*}{19 September 2003} & I & $\mathrm{C} 4$ & $23: 31: 37$ & $23: 31: 46$ & $23.1 \pm 0.8$ & -3.9 & $48.7 \pm 1.8$ \\
\hline & $\mathrm{P}$ & $\mathrm{C} 4$ & $23: 32: 14$ & $23: 32: 24$ & $19.7 \pm 1.4$ & -3.5 & \\
\hline & $\mathrm{C}$ & $\mathrm{C} 4$ & $23: 31: 48$ & $23: 31: 53$ & $11.9 \pm 0.6$ & -3.3 & \\
\hline & $\mathrm{S}$ & $\mathrm{C} 4$ & $23: 30: 28$ & $23: 30: 42$ & $6.2 \pm 0.4$ & -3.2 & \\
\hline \multirow{2}{*}{4 October 2003} & $\mathrm{~S}$ & $\mathrm{C} 4$ & $06: 20: 12$ & $06: 20: 21$ & $1.0 \pm 0.2$ & -2.7 & $1.5 \pm 0.2$ \\
\hline & I & $\mathrm{C} 4$ & $06: 20: 25$ & $06: 20: 34$ & $1.0 \pm 0.2$ & -2.8 & \\
\hline \multirow[t]{3}{*}{14 September 2004} & $\mathrm{~S}$ & $\mathrm{C} 1$ & $23: 04: 43$ & $23: 05: 03$ & $18.5 \pm 2.2$ & -1.7 & $18.5 \pm 2.2$ \\
\hline & $\mathrm{P}$ & $\mathrm{C} 2$ & $23: 06: 32$ & $23: 06: 48$ & $18.1 \pm 1.1$ & -3.4 & \\
\hline & $\mathrm{C}$ & $\mathrm{C} 1$ & $23: 04: 28$ & $23: 04: 36$ & $14.2 \pm 2.0$ & -1.6 & \\
\hline \multirow[t]{3}{*}{28 August 2005} & $\mathrm{C}$ & $\mathrm{C} 4$ & $23: 42: 19$ & $23: 42: 26$ & $8.0 \pm 0.6$ & -3.1 & $8.3 \pm 0.5$ \\
\hline & $\mathrm{P}$ & $\mathrm{C} 3$ & $23: 45: 32$ & $23: 45: 39$ & $4.3 \pm 0.3$ & -4.3 & \\
\hline & I & $\mathrm{C} 3$ & $23: 40: 11$ & $23: 40: 20$ & $0.2 \pm 0.1$ & - & \\
\hline
\end{tabular}

current layer. Figure 5 displays the locations of the most efficient energizations as a function of reconnecting magnetic field $B_{x}$ and plasma outflow speed $V_{x}$. The energization occurs in a broad regime from $B_{x}=-0.8 B_{0}$ to $B_{x}=0.8 B_{0}$ and from $V_{x}=-0.5 V_{A}$ to $V_{x}=0.5 V_{A}$. There are more data points within the earthward flow than those within the tailward flow. The reason for this asymmetry is yet unknown.

Our results do not contradict with recent results that emphasize the dominant role played by the earthward moving dipolarization fronts in electron energization in the near-tail region (e.g. Ashour-Abdalla et al., 2011). This is because we focus on the region around the neutral line beyond $\mathrm{X} \sim-15$ $R_{\mathrm{E}}$, where the flux pileup region/dipolarization front is just produced. Whereas most observations of energized electrons associated with dipolarization fronts were made at $\mathrm{X}>-15$ $R_{\mathrm{E}}$, where electrons have been interacted with the electric field associated with the flux pileup region in sufficient time. 
Electrons inside these structures may drift from other acceleration sites. In particular, Duan et al. (2014) found that most energetic electrons in plasma sheet are directly or indirectly associated with magnetic reconnection, but some energetic electron burst is not caused by local acceleration. Actually we cannot determine the relative contribution of these two factors (local acceleration and drift-in effect) in any of the four structures. What we confirm is that local acceleration exists inside all four structures, as we have described in the introduction section. If the two factors coexist in one structure, take magnetic island for example, electrons trapped within the island may come from the thin current sheet, where they have been energized. Then these electrons are further energized inside the island. Hence the acceleration efficiency within the island is higher than that within the current sheet. What we emphasize is the resultant efficiency, which is determined by the two factors even though we do not know the relative contributions from them based on the present study.

Interestingly, one may notice that, in some of the events, the highest flux ratio corresponds to the lowest power law index, such as the 22 August 2001, 12 September 2001, 15 September 2001, 1 October 2001, 2 October 2002 and 19 September 2003 event. Because not only the power law index but also the effective temperature affects the flux ratio, we suggest that in some cases electrons are substantially heated so the ratio is high even though the spectrum is relatively softer.

We also note that the maximum ratio for each event usually does not locate in the four structures. It means that the most efficient energization of electrons occurs outside these structures. Although many previous studies focus on the electron energization inside these four structures, what we learn from this study is that, other structures (except the four we discussed) may be more important for electron energization and worth paying more attention to in future studies.

Acknowledgements. We thank the Cluster teams and the Cluster Science Archive for providing high-quality data. This work was supported by the National Science Foundation of China (NSFC) under grants 41174147, 41274170, 41331070, 41522405 and Science Foundation of Jiangxi Province under grant 20142BCB23006. M. Z was also supported by the Specialized Research Fund for State Key Laboratories. All the data presented in this paper were downloaded freely from the Cluster Science Archive (http://www.cosmos.esa. int/web/csa/access).

The topical editor E. Roussos thanks the two anonymous referees for help in evaluating this paper.

\section{References}

Ashour-Abdalla, M., El-Alaoui, M., Goldstein, M., Zhou, M., Schriver, D., Richard, R., Walker, R., Kivelson, M. G., and Hwang, K.: Observations and Simulations of Nonlocal Acceleration of Electrons in Magnetotail Magnetic Reconnection Events, Nat. Phys., 7, 360-365, doi:10.1038/nphys1903, 2011.

Balogh, A., Carr, C. M., Acuña, M. H., Dunlop, M. W., Beek, T. J., Brown, P., Fornacon, K.-H., Georgescu, E., Glassmeier, K.H., Harris, J., Musmann, G., Oddy, T., and Schwingenschuh, K.: The Cluster Magnetic Field Investigation: overview of in-flight performance and initial results, Ann. Geophys., 19, 1207-1217, doi:10.5194/angeo-19-1207-2001, 2001.

Borg, A. L., Taylor, M. G. G. T., and Eastwood, J. P.: Observations of magnetic flux ropes during magnetic reconnection in the Earth's magnetotail, Ann. Geophys., 30, 761-773, doi:10.5194/angeo-30-761-2012, 2012.

Cattell, C., Dombeck, J., Wygant, J., Drake, J. F., Swisdak, M., Goldstein, M. L., Keith, W., Fazakerley, A., André, M., Lucek, E., and Balogh, A.: Cluster observations of electron holes in association with magnetotail reconnection and comparison to simulations, J. Geophys. Res., 110, A01211, doi:10.1029/2004JA010519, 2005.

Chen, L.-J., Bhattacharjee, A., Puhl-Quinn, P. A., Yang, H., Bessho, N., Imada, S., Muhlbachler, S., Daly, P. W., Lefebvre, B., Khotyaintsev, Y., Vaivads, A., Fazakerley, A., and Georgescu, E.: Observation of energetic electrons within magnetic islands, Nat. Phys., 4, 19-23, doi:10.1038/nphys777, 2008.

Dahlin, J. T., Drake, J. F., and Swisdak, M.: Electron acceleration in three-dimensional magnetic reconnection with a guide field, Phys. Plasmas, 22, 100704, doi:10.1063/1.4933212, 2015.

Deng, X. H., Matsumoto, H., Kojima, H., Mukai, T., Anderson, R. R., Baumjohann, W., and Nakamura, R.: Geotail encounter with reconnection diffusion region in the Earth's magnetotail: Evidence of multiple X lines collisionless reconnection?, J. Geophys. Res., 109, A05206, doi:10.1029/2003JA010031, 2004.

Deng, X., Ashour-Abdalla, M., Zhou, M., Walker, R., El-Alaoui, M., Angelopoulos, V., Ergun, R. E., and Schriver, D.: Wave and Particle Characteristics of Earthward Electron Injections Associated with Dipolarization Fronts, J. Geophys. Res., 115, A09225, doi:10.1029/2009JA015107, 2010.

Drake, J. F., Shay, M. A., and Thongthai, W.: Production of energetic electrons during magnetic reconnection, Phys. Rev. Lett., 94, 095001, doi:10.1103/PhysRevLett.94.095001, 2005.

Drake, J. F., Swisdak, M., Che, H., and Shay, M. A.: Electron acceleration from contracting magnetic islands during reconnection, Nature, 443, 7111, 553-556, 2006.

Duan, A. Y., Cao, J. B., Dunlop, M., and Wang, Z. Q.: Energetic electron bursts in the plasma sheet and their relation with BBFs, J. Geophys. Res. Space Physics, 119, 8902-8915, doi:10.1002/2014JA020169, 2014.

Eastwood, J. P., Phan, T.-D., Mozer, F. S., Shay, M. A., Fujimoto, M., Retinò, A., Hesse, M., Balogh, A., Lucek, E. A., and Dandouras, I.: Multi-point observations of the Hall electromagnetic field and secondary island formation during magnetic reconnection, J. Geophys. Res., 112, A06235, doi:10.1029/2006JA012158, 2007.

Egedal, J., Daughton, W., and Le, A.: Large-scale electron acceleration by parallel electric fields during magnetic reconnection, Nat. Phys. 8, 321-324, 2012. 
Fu, H. S., Khotyaintsev, Y. V., Vaivads, A., Retinò, A., and André, M.: Energetic electron acceleration by unsteady magnetic reconnection, Nat. Phys., 9, 426-430, doi:10.1038/NPHYS2664, 2013.

Gustafsson, G., André, M., Carozzi, T., Eriksson, A. I., Fälthammar, C.-G., Grard, R., Holmgren, G., Holtet, J. A., Ivchenko, N., Karlsson, T., Khotyaintsev, Y., Klimov, S., Laakso, H., Lindqvist, P.-A., Lybekk, B., Marklund, G., Mozer, F., Mursula, K., Pedersen, A., Popielawska, B., Savin, S., Stasiewicz, K., Tanskanen, P., Vaivads, A., and Wahlund, J.-E.: First results of electric field and density observations by Cluster EFW based on initial months of operation, Ann. Geophys., 19, 1219-1240, doi:10.5194/angeo19-1219-2001, 2001.

Hoshino, M., Mukai, T., Terasawa, T., and Shinohara, I.: Suprathermal electron acceleration in magnetic reconnection, J. Geophys. Res., 106, 4509-4530, 2001.

Huang, S. Y., Vaivads, A., Khotyaintsev, Y. V., Zhou, M., Fu, H. S., Retinò, A., Deng, X. H., André, M., Cully, C. M., He, J. S., Sahraoui, F., Yuan, Z. G., and Pang, Y.: Electron acceleration in the reconnection diffusion region: Cluster observations, Geophys. Res. Lett., 39, L11103, doi:10.1029/2012GL051946, 2012a.

Huang, S. Y., Zhou, M., Deng, X. H., Yuan, Z. G., Pang, Y., Wei, Q., Su, W., Li, H. M., and Wang, Q. Q.: Kinetic structure and wave properties associated with sharp dipolarization front observed by Cluster, Ann. Geophys., 30, 97-107, doi:10.5194/angeo-30-972012, 2012b.

Imada, S., Nakamura, R., Daly, P. W., Hoshino, M., Baumjohann, W., Mühlbachler, S., Balogh, A., and Rème, H.: Energetic electron acceleration in the downstream reconnection outflow region, J. Geophys. Res., 112, A03202, doi:10.1029/2006JA011847, 2007.

Imada, S., Hirai, M., Hoshino, M., and Mukai, T.: Favorable conditions for energetic electron acceleration during magnetic reconnection in the Earth's magnetotail, J. Geophys. Res., 116, A08217, doi:10.1029/2011JA016576, 2011.

Johnstone, A. D., Alsop, C., Burge, S., Carter, P. J., Coates, A. J., Coker, A. J., Fazakerley, A. N., Grande, M., Gowen, R. A., Gurgiolo, C., Hancock, B. K., Narheim, B., Preece, A., Sheather, P. H., Winningham, J. D., and Woodliffe, R. D.: PEACE: A plasma electron and current experiment, Space Sci. Rev., 79, 351-398, doi:10.1023/A:1004938001388, 1997.

Øieroset, M., Lin, R. P., Phan, T. D., Larson, D. E., and Bale, S. D.: Evidence for electron acceleration up to $300 \mathrm{keV}$ in the magnetic reconnection diffusion region of Earth's magnetotail, Phys. Rev. Lett., 89, 195001, doi:10.1103/PhysRevLett.89.195001, 2002.

Pedersen, A., Lybekk, B., André, M., Eriksson, A., Masson, A., Mozer, F. S., Lindqvist, P.-A., Décréau, P. M. E., Dandouras, I., Sauvaud, J.-A., Fazakerley, A., Taylor, M., Paschmann, G., Svenes, K. R., Torkar, K., and Whipple, E.: Electron density estimations derived from spacecraft potential measurements on Cluster in tenuous plasma regions, J. Geophys. Res., 113, A07S33, doi:10.1029/2007JA012636, 2008.

Pritchett, P. L.: Relativistic electron production during guide field magnetic reconnection, J. Geophys. Res., 111, A10212, doi:10.1029/2006JA011793, 2006.

Rème, H., Aoustin, C., Bosqued, J. M., Dandouras, I., Lavraud, B., Sauvaud, J. A., Barthe, A., Bouyssou, J., Camus, Th., Coeur-Joly, O., Cros, A., Cuvilo, J., Ducay, F., Garbarowitz, Y., Medale, J.
L., Penou, E., Perrier, H., Romefort, D., Rouzaud, J., Vallat, C., Alcaydé, D., Jacquey, C., Mazelle, C., d'Uston, C., Möbius, E., Kistler, L. M., Crocker, K., Granoff, M., Mouikis, C., Popecki, M., Vosbury, M., Klecker, B., Hovestadt, D., Kucharek, H., Kuenneth, E., Paschmann, G., Scholer, M., Sckopke, N., Seidenschwang, E., Carlson, C. W., Curtis, D. W., Ingraham, C., Lin, R. P., McFadden, J. P., Parks, G. K., Phan, T., Formisano, V., Amata, E., Bavassano-Cattaneo, M. B., Baldetti, P., Bruno, R., Chionchio, G., Di Lellis, A., Marcucci, M. F., Pallocchia, G., Korth, A., Daly, P. W., Graeve, B., Rosenbauer, H., Vasyliunas, V., McCarthy, M., Wilber, M., Eliasson, L., Lundin, R., Olsen, S., Shelley, E. G., Fuselier, S., Ghielmetti, A. G., Lennartsson, W., Escoubet, C. P., Balsiger, H., Friedel, R., Cao, J.-B., Kovrazhkin, R. A., Papamastorakis, I., Pellat, R., Scudder, J., and Sonnerup, B.: First multispacecraft ion measurements in and near the Earth's magnetosphere with the identical Cluster ion spectrometry (CIS) experiment, Ann. Geophys., 19, 1303-1354, doi:10.5194/angeo19-1303-2001, 2001.

Retinò, A., Nakamura, R., Vaivads, A., Khotyaintsev, Y., Hayakawa, T., Tanaka, K., Kasahara, S., Fujimoto, M., Shinohara, I., Eastwood, J. P., André, M., Baumjohann, W., Daly, P. W., Kronberg, E. A., and Cornilleau-Wehrlin, N.: Cluster observations of energetic electrons and electromagnetic fields within a reconnecting thin current sheet in the Earth's magnetotail, J. Geophys. Res., 113, A12215, doi:10.1029/2008JA013511, 2008.

Runov, A., Nakamura, R., Baumjohann, W., Treumann, R. A., Zhang, T. L., Volwerk, M., Voros, Z., Balogh, A., Glaßmeier, K.H., Klecker, B., Rème, H., and Kistler, L.: Current sheet structure near magnetic X-line observed by Cluster, Geophys. Res. Lett., 30, 1579, doi:10.1029/2002GL016730, 2003.

Sonnerup, B. U. O.: Magnetic field reconnection, in Solar System Plasma Physics, vol. 3, 45-118, Elsevier, New York, 1979.

Wang, R., Du, A., Nakamura, R., Lu, Q., Khotyaintsev, Y. V., Volwerk, M., Zhang, T., Kronberg, E. A., Daly, P. W., and Fazakerley, A. N.: Observation of multiple sub-cavities adjacent to single separatrix, Geophys. Res. Lett., 40, 2511-2517, doi:10.1002/grl.50537, 2013.

Wilken, B., Daly, P. W., Mall, U., Aarsnes, K., Baker, D. N., Belian, R. D., Blake, J. B., Borg, H., Büchner, J., Carter, M., Fennell, J. F., Friedel, R., Fritz, T. A., Gliem, F., Grande, M., Kecskemety, K., Kettmann, G., Korth, A., Livi, S., McKenna-Lawlor, S., Mursula, K., Nikutowski, B., Perry, C. H., Pu, Z. Y., Roeder, J., Reeves, G. D., Sarris, E. T., Sandahl, I., Søraas, F., Woch, J., and Zong, Q.-G.: First results from the RAPID imaging energetic particle spectrometer on board Cluster, Ann. Geophys., 19, 1355-1366, doi:10.5194/angeo-19-1355-2001, 2001.

Zhou, M., Ashour-Abdalla, M., Deng, X., Schriver, D., ElAlaoui, M., and Pang, Y.: THEMIS observation of multiple dipolarization fronts and associated wave characteristics in the near-Earth magnetotail, Geophys. Res. Lett., 36, L20107, doi:10.1029/2009GL040663, 2009.

Zhou, M., Pang, Y., Deng, X. H., Yuan, Z. G., and Huang, S. Y.: Density cavity in magnetic reconnection diffusion region in the presence of guide field, J. Geophys. Res., 116, A06222, doi:10.1029/2010JA016324, 2011.

Zhou, M., Deng, X. H., and Huang, S. Y.: Electric field structure inside the secondary island in the reconnection diffusion region, Phys. Plasmas, 19, 042902, doi:10.1063/1.3700194, 2012. 
Zhou, M., Li, H., Deng, X., Huang, S., Pang, Y., Yuan, Z. $\mathrm{Xu}, \mathrm{X}$., and Tang, R.: Characteristic distribution and possible roles of waves around the lower hybrid frequency in the magnetotail reconnection region, J. Geophys. Res.-Space, 119, doi:10.1002/2014JA019978, 2014.
Zhou, M., Deng, X., Li, H., and Huang, S.: Statistics of energetic electrons in magnetotail reconnection, J. Geophys. Res.-Space, in review, 2015. 